\title{
Potential, Pitfalls and Challenges in Development of ICT in Education
}

\author{
Anil Kumar Pandey* \\ Email: anilpandeybhu[at]yahoo.com \\ Computer Centre, Banaras Hindu University, \\ Varanasi Uttar Pradesh-221011
}

\section{Introduction}

Information and communication technologies (ICTs) imparts vital role in field of education globally particularly in developing countries and to their use in education. This paper discuss the role of ICT in education is well demanding. The scenario of global development is seems completely on the platform of ICT in this century. ICTs has arisen a powerful tool in the field of education globally. The pros and cons in the development of ICT and uses to meet out the requirement of community. ICTs, fundamentally a tools of collection application to provide information to the community. According to United Nation Development Programme (UNDEP) Information and Communication Technologies (ICTs) deals with most high handled and costly computer based technologies. ICT also added through the traditional information system such as telephone, radio, television and the satellite and wireless technology. There are various tolls are available in ICT to develop and produce, store and process the information by using good software techniques.

ICTs facilitates with different tools that are now able to work together, and combine to form our ,networked world $^{\text {ee }}$ - a massive infrastructure of interconnected telephone services, standardized video cassettes, CDs and Memory drives. In the history of ICT the basic concept was based on Analogue media but in the current scenario the digital media has superimposed Analogue media through the internet based Technologies. The combination of satellite and computer boom the technology and draw a partition between analogue and Digital. People are very blurred in the definition of ICTs. The concept of new and old are visualised by people. A generation gap of technology appears in well form and a process of blend is going on to upgrade old media into new one. The ancestors who were aware with analogue media being transferring concept in form of digital. A gap between both creates a line of development of technologies. ICTs is changing nature of user and learner, well demand of education for all. The idea based on linearization, privatisation and globalisation forms the current socio-economic, technological and political space with help and support of technology to access, equity and resources. An information revolution has changed the boundary of knowledge in global as well as countries. In the new era education has got place within twelve main services which required to be opened for free flow for trade between countries. Nowadays knowledge is treated as essential tradable commodity in the world. GATs come into complete way in after negotiation among participating countries. The trade between the countries with the interdependence media and completion will closely change the availability, affability, attractiveness on social economical forum. The ICTs will boom up the socio-cultural and educational relationship with the countries. The education is quite demanding on the platform of World economy. There is a scenario of changes in capabilities. The interest of users and changes capabilities requires at the same time medium and contents, the freedom of media and completion between them to survive on the socio-economic platform. The demand of ICT prevail the developer of INCT in free atmosphere. They are always trying to upliftment of technology to meet out the demand of users in changing capabilities. The social media become powerful instrument in the developing and developed countries. It is quite amazing that the changing in the technologies versions are highly appreciable and being used freely by the community especially in education system.

India has second world leading population country here fifty percent of the population of age below 15 years, seventy five percent of rural and literacy rate about 60 percent with 15 different languages throughout the country and also in terms the urban-rural access, equity, and resources in the context, particularly adult educators will have to address as the needs of the learning community in the new social, economic and political contexts will change.

The new education system divided the society into four levels of learners. The first level of learners having students they are in position to afford the high cost of education so called elites can get best facility from either public or private institutions of higher education. They are using best facility with help of high cost and high quality principle basis. The bright, intelligent and competent students, those are not able to afford high quality costly education will attain education from public and will be competing first level for membership in the race of education leaders. A third level of students will consist of the academically and financially poor students, who access to education from lower quality institutions of higher learning. And the last but not the least group of learners are those who are illiterate and the poor. In order to enhance ICT based learning system multiple level of trained individual educator well equipped with technology is required. It is high time of deploying technology to meet the aim of education for all. The technology will definitely improve the quality and quantity of educated people. 


\section{International Journal of Science and Research (IJSR) \\ ISSN (Online): 2319-7064}

Index Copernicus Value (2015): 78.96 | Impact Factor (2015): 6.391

The technology support model of education will brings the role of teacher and educator onto focus. The role of adult educator is very high and important in delivery process of education to the learner. The responsibilities of the teachers or adult educators are many, and very often they feel threatened and further challenged when told that they have to use ICTs, sometimes even feeling that they may well lose their jobs or be replaced by the ICTs. ICTs have also strengths and weaknesses like other innovation. We have to accept ICTs in positive in strength manner. Some of the strengths of the ICTs include:

- Individualization of learning: This means that people learn as individuals and not as a homogenous group. ICTs allow each individual to relate to the medium and its content.

- Interactivity: Interactivity is the way in which a person can relate to the content, go forward and backward in the content, start at any point depending upon prior knowledge instead of always in a sequential way.

- Low per unit cost: Per person, ICTs reduce the cost of education from very high to very low.

- Distance and climate insensitive: It does not matter where you are, or how the weather is, you can still access and learn from ICTs.

- Can serve multiple teaching functions and diverse audiences: ICTs, especially the computer and Internet based can be useful in drill and practice; to help diagnose and solve problems, for accessing information and knowledge about various related themes.

- High speed delivery and wide reach at low cost: There is instant delivery of information.

- Uniform quality: If content is well produced and is of good quality, the same quality can be delivered to the rich and the poor, the urban and the rural equally and at the same low cost. But ICTs also have weaknesses which we must understand.

- High infrastructure and start up costs: It costs money to build ICT systems and to maintain them.

- Tend toward centralized uniform content in economies of scale: The larger the numbers, the lower the cost. This means that sometimes we try to reach large numbers so we make content common, not taking into account individual differences.

- Are not ideally location and problem sensitive: Address problems in a general way, but cannot, without special effort, solve local and culturally sensitive problems.

- Problems of reach and accessibility: Not everyone has equal access; so not everyone benefits equally from the use of ICTs.

- Tend to create new class of knowledge rich/knowledge poor:Those who have access and knowledge through the media become richer and those who do not become poorer, widening the "knowledge or digital gap" between rich and poor.

- Essentially delivery systems: A medium is different from the content; and often we forget that we can deliver any content, because ICTs are essentially meant only to deliver content, not to change attitudes or bring about behaviour change.

- Hard to assess impact: Learning from ICT delivered content is difficult to assess since such learning is of a multidimensional and long term kind, rather than from immediate learning assessment as in a classroom test.

- Orientation Programme for officer and Trainer: People should learn use of ICTs and officers required training, reorientation support of training. People are in practice of training in tradition system in orientation programme. There is need of time to change the process and mechanism of training schedule and process to educate the people those have aware about the programme and having capacity to accept the technological changes. The trading system of learning have taken place like radio and television. The training supervisor may be instructed to learn advance ICT and use it as a training tools in the process of training and education. It is well when we use ICTs in the strength manner after a good plan and effort. Further poverty, illiteracy, mobility relevance, socio cultural factors are the key factors of influencing access.

- Ownership and Control: The basis of access is depends upon ownership and control. The other things about poor, illiterate, rural women are unable to accept the technology due lack of knowledge and awareness. Due these facts ownership and control cannot be provided with the fact ownership and control is related to communication bring involvement and commitment. They enable people to use the technologies to give voice to their own needs and to create their own materials. And when ownership and control is transferred to the community, the likelihood of change is greater and the ICTs break down barriers when technology is demystified.

- Technology driven vs. People driven: A third myth places the technology first. "The technology worked, but the effort did not yield results" is a common assessment of projects using ICTs. This is because the bulk of investment in any project generally goes toward such overhead costs and few resources are left for project activities. People issues must be addressed first. Choice and use of ICTs depends upon the investment in people first, rather than on the deployment of sophisticated ICT based "solutions" without adequate attention to the people issues.

- Content matters: That content for technology is readily available and if not it is easy to develop is the fourth misconception about ICTs. There are aspects of content development i.e. relevant, timely, local content, Multimedia content suitable to be used by the new ICTs takes longer and costs more.

- Participation: Who determines what is relevant, timely and local? there is less chance of actual use to learner. Relevant, appropriate, time and problem solving content is critical. It may be developed with partnership of learner

- Appropriate ICTs: The most appropriate medium may be examined and applied. There should issue of reach and access of technology both hardware and software with content relevance, cultural acceptability and usability.

- Ground support: It includes community enlistment and participation; timely availability of support materials, whether of fertilizers or books or literacy primers. 


\section{International Journal of Science and Research (IJSR) \\ ISSN (Online): 2319-7064}

Index Copernicus Value (2015): 78.96 | Impact Factor (2015): 6.391

\section{Conclusion}

It can be concluded that through using of Information and Communications Technology (ICT) in Education can help to enhance the possibilities of better learning outcomes. So following parameters should be taken into account.

1. There is need of new form of interaction between students, teachers, education employees and the community and enhance the quality of education by making it more accessible.

2. There is need of coordination with Technology and traditional education system. The educational activities should be incorporated with application of ICT.

3. ICT has in position to cope up the learning process to enhance the learning process and facilitate communications within education.ICT should work as intelligent agent between educator and learner.

4. Education providers should make a proper way to utilize ICT for betterment of student as well as community on low cost and high performance basis.

5. Government should make a policy for promotion of ICT in education with consultation within education.

6. The commercial ICT companies should be engaged in development of content with help and support of educator and learner with adequate acceptable manner in the community.

\section{References}

[1] Bandura, A. (1986). Social foundations of thought and action: A Social-Cognitive View. Englewood cliffs, NJ: Prentice-Hall

[2] Brosnan, T. (2001). Teaching Using ICT. University of London: Institute of Education.

[3] Carnoy, M. (2002). ICT in Education: Possibilities and Challenges. (Downloaded from: http://www. uoc.edu, 04 March 2011).

[4] Hare, H. (2007). Survey of ICT and Education in Africa: Ethiopia Country Report (ICT in Education in Ethiopia). www.infodev.org downloaded February 28

[5] Jonassen, D.H. (1991). Objectivism versus constructivism: Do we need a new philosophical paradigm? Educational Technology Research and development, 39(3), 5-14

[6] Kok, A. (2007). ICT Integration into Classrooms: Unpublished literature review Kozma, R.B, (2005).National policies that connect ICT-based education reform to economic and social development. An interdisciplinary journal of humans in ICT environment 1(2) 117-156

[7] Kulik, J.A. (1994).Meta-analytic studies of findings on computer-based instruction. In J.E.L.Baker \&H.F.O'Neil (Ed.), Technology Assessment in Education and Training. Hillsdale, NJ: Lawrence Erlbaum

[8] OECD. (2002). ICT: Policy Challenges for Education. Planning Meeting, Agenda and Issue Paper. (Retrieved from https://www.oecd.org/LongAbstract on December 2009)

[9] Olson, J. (2000). Trojan horse or Teacher"s Pet? Computer and the Culture of the School. Journal of Curriculum Studies, 32 (1), 1-8.
[10]Pedro et.al. (2004). Technology in Schools: Education, ICT and the Knowledge Society. (Retrieved from http://www.worldbank.org/education/pdf/ic t_report_oct04.pdf on December 2009)

[11] Tinio, V.L. (2002). ICT in Education: UN Development Programme. (Retrieved from http:www.eprmers.org on December 2009)

[12]UNDP. (2004). Promoting ICT for Human Development. A Pioneering Regional Human Development Report in Asia in 2004: Realizing the Millennium Development Goals (Retrieved from http://www.apdip.net/projects/rhdr/resources/PDF on December 2009

[13] Volman, M. (2005). Variety of roles for a new type of teacher. Educational technology and the teacher profession. Teacher and Teacher Education, 21, 15-31.

[14] Voogt, J. (2003). Consequences of ICT for aims, contents, processes, and environments of learning. In J. van den Akker, W. Kuiper \& U. Hameyer (Eds.), Curriculum landscapes and trends (pp 217 - 236). Dordrecht: Kluwer Academic Publishers.

[15] Watson, D.M. (2001). Pedagogy before Technology: Re-thinking the Relationship between ICT and Teaching. Education and Information Technologies, 6, 4, 251-266.

[16] Yousef, A. B. and Dahamini, M. (2008). The Economics of E- Learning: The Impact of ICT on Student Performance in Higher Education: Direct Effects, Indirect Effects and Organizational Change (http://rusc.uoc.edu, downloaded March 4, 2011) 